\title{
A 54-point verbal-performance IQ discrepancy on the WISC-R: cognitive functioning of a child from an alternative school
}

\author{
D. Lapierre' ${ }^{1}$ C.M.J. Braun ${ }^{1}$ and L. Le Pailleur ${ }^{2}$ \\ ' Université du Québec à Montréal, Département de Psychologie, C.P. 8888, Succ. "A", \\ Montréal, Québec H3C 3P8, Canada, and 'Université de Montréal, Québec, Canada
}

\begin{abstract}
Marked WISC-R verbal-performance discrepancy commonly leads to the assumption that such children have brain pathology or cognitive disorders. Children without brain dysfunction may also exhibit wide discrepancy, but a discrepancy score of 30 is assumed to occur in only $2 \%$ of the population. The actual investigation presents an 11-year-old child showing a 54-point discrepancy between the two scales of the WISC-R. Results of wide ranging testing and other considerations strongly suggested that this child didn't manifest any kind of brain dysfunction. It was concluded that the particular academic environment of the child, an alternative school, exerted a very strong influence on her results on the WISC-R. This conclusion is furthermore supported by the results of a follow-up evaluation, done 1 year after the child has been transferred to a traditional school, which revealed a WISC-R verbal-performance discrepancy of only 12 points.
\end{abstract}

Keywords: Academic achievement - Clinical neuropsychology - EEG - Learning disabilities - VIQ-PIQ - WISC-R

\section{INTRODUCTION}

The analysis of profiles obtained on the Wechsler Adult Intelligence Scale (WAIS; Wechsler, 1955) and on the Wechsler Intelligence Scale for Children-Revised (WISC-R; Wechsler, 1974) has become common practice among neuropsychological clinicians. Guidelines have been sought for the evaluation of the clinical significance of observed profiles, particularly the discrepancies between verbal (V) and performance (P) scale IQs (VIQ-PIQ discrepancies). WISC-R VIQ-PIQ discrepancies often appear to be associated with a substantial variety of perinatal, verbal, visuospatial, motor, and neurological disorders including EEG abnormalities (Black, 1974; Holroyd, 1968).

Various investigations of brain-injured adults tested on the WAIS found mean VIQ-PIQ discrepancies of more or less 25 points (Inglis and Lawson, 1982; Bornstein, 1984; McGlone, 1986). Conceivably, effects of brain dysfunction on the VIQ-PIQ discrepancy could be very different in children. On the one hand, those effects could be more dramatic than in adults because of failure of hemisphere-damaged children to acquire functions that are hemispherically lateralized. On the other hand, they could be less salient than in adults because of greater adaptative plasticity of the maturing brain. Of course, both processes could also be operative and tend to cancel out.

Gutkin (1979) tested minimally brain injured children on the WISC-R and reported a mean VIQ-PIQ difference of 12 points. A study of three children who had been hemidecorticated at birth reported no VIQ-PIQ discrepancies higher than 17 points (Dennis and Whitaker, 1976). Groups of mildly retarded children and of severe learning disabled children were tested by Bloom et al. (1986) and discrepancies of 25 points or less were reported. Mentally retarded children evaluated by Thompson (1980) showed a mean discrepancy of 8 points. Saklofske et al. (1984) observed a mean VIQ-PIQ difference of 15 points among learning disabled children. Other studies concerning this particular population reported mean discrepancies of less than 18 points (Tabachnick, 1979; Thompson, 1980; Ryckman, 1981; Schiff et al., 1981). In fact, Kaufman (1981) stated that even though learning-disabled children often show a significant scatter in their test results, this scatter is rarely high enough to justify particular practical consequences. This group does not seem to be associated with consistently abnormal scatter in WISC-R profiles.

Lower VIQ scores tend to be consistantly attributed to left hemisphere lesions and lower PIQ scores to right hemisphere lesions (Bornstein and Matarazzo, 1982; Inglis and Lawson, 1982; Bornstein, 1984). However, the evidences are not always consistent regarding this issue. Vargha-Khadem et al. (1985) stated that postnatally acquired left hemisphere lesions resulted in lower VIQ while postnatally acquired right hemisphere lesions produced lower PIQ. Riva and Cazzaniga (1986) observed 
that, regardless of age, right hemisphere lesions resulted in lower PIQ while left hemisphere lesions resulted in both lower VIQ and PIQ. Finally, Aram and Whitaker (1988) found that VIQ-PIQ discrepancies could not distinguish between right- and left-lesioned children.

Even though Wechsler (1974) stated that a difference between verbal and performance IQs of at least 15 points is required to necessitate deeper investigation, Kolb and Whishaw (1985) noted that a split of 10 points between the verbal and performance scores is generally conceived as clinically significant. In the same way, a cut-off of 10 points was established by Lueger et al. (1986) as the criterion for abnormal discrepancy among children hospitalized for numerous motives.

Although strong evidence has accumulated to suggest that children with diverse cognitive disorders have elevated rates of relatively wide VIQ-PIQ discrepancies, it is now well known that an abnormal score does not necessarily signal a clinically pathological child from the general population. Kaufman $(1976,1980)$ insisted on restricting diagnostic judgements to wider discrepancies. In fact, he pointed out that the normal population shows a somewhat greater rate of scatter on the WISC-R than was previously assumed. Kaufman demonstrated that about one quarter of the WISC-R standardization sample had discrepancies of 15 points or more. He then suggested the use of a criterion of statistical abnormality for VIQ-PIQ discrepancies of 20 points (less than $12 \%$ prevalence) or for discrepancies of 30 points (less than $2 \%$ prevalence).

Supporting this view, Moffitt and Silva (1987) examined children from an unselected cohort who manifested VIQ-PIQ discrepancies of about 23 points. Their results determined that neither perinatal difficulties, childhood neurological abnormalities, or concussions were found to be more wide-spread among children with such a high discrepancy than among children with a flat profile. The idea that WISC-R VIQ-PIQ discrepancies are not consistently associated with neurological, developmental, learning or emotional disorders, and that a normal child may exhibit discrepancies as high as 25 points now seems strongly supported.

The case study reported here wishes to highlight the potential role that different factors, mainly the educational environment, can have on the VIQ-PIQ difference scores of an apparently normal child by presenting Mélodie, an 11-year-old French-Canadian girl who manifested a WISC-R verbal-performance IQ discrepancy of 54 points in favor of the performance scale (VIQ = 96; PIQ = 150; FSIQ = 124). The parents and child requested that Mélodie's real first name be used in the present report. The mother of the child informally consulted a neuropsychological clinician who told her that her daughter was certainly not normal, probably had severe difficulties in sequential processing and most probably suffered from a left hemisphere brain lesion. Furthermore, a special educator formally examined the girl's academic abilities using a battery of tests and classified her as having severe learning disabilities. Many tests were then administered to Mélodie in order to verify the presence of a cerebral lesion and of a severe learning disability. Before presenting the various results of those tests, it seems appropriate to describe the child's past history, particularly concerning her health, language acquisition and school achievement.

\section{ANAMNESIS}

Mélodie's mother's pregnancy and labor required no medication and proceeded without any sort of complication. The baby was in good health. Mélodie never suffered from any major infantile illness, never received any antibiotic, was never hospitalized, never lost consciousness and was never the victim of a head trauma. The child always developed regularly, though slightly below norm for height and weight.

Mélodie began to speak spontaneously and rapidly gained a good vocabulary. At 10 months, she consistently turned books around so that the pictures would always face her and she attentively looked at the pages. At 15 months, she could easily say her own name and could name familiar objects surrounding her. At 24 months, she had a fairly good pronunciation and was easily understood. During this period, Mélodie moved from Quebec and lived 15 months in India with her family. There, she quickly learned an Indian dialect mixed with English spoken by the Indian children. Upon her return home, Mélodie forgot that language and has never had the opportunity to acquire a language other than her maternal French since then.

Mélodie's kindergarten class was in a traditional school. The program of that year included preparatory exercises for writing. In first grade, Mélodie was transfered to an alternative school with "free pedagogy". This type of school offers the child the opportunity to learn traditional academic subjects (French, reading, mathematics, etc.) but the child is always left free to participate in such activities or not. During her first 2 years at that school, Mélodie learned the alphabet and a few syllables, but showed no strong interest in reading. She was also taught to write by sound. She therefore did not acquire any strict grammatical rules. Mélodie mainly concentrated on artistic activities where she could express her great creativity, and deliberately retarded her traditional academic learning. By the middle of her third grade, Mélodie could read only rather slowly. She was then transfered to another alternative school with open pedagogy where a few hours of French and mathematics were compulsory each week. At that time, Mélodie was evaluated by a special educator as having barely attained the normal first grade level of achievement. She showed an evident lack of basic knowl- 
edge in French and in mathematics, but she excelled in geometry and artistic activities.

At the time of the first WISC-R evaluation, Mélodie was in fifth grade in the same school, was 11 years old, and had made little progress in traditional academic subjects. She could read quite well, but presented a lot of confusion in grammatical rules, still writing according to the sound of the words. Her oral expression was perfect and she could write complete and original stories with a logical organisation. She performed rather poorly in mathematics. According to her mother, Mélodie never had more than an hour of homework to do each week.

During her fifth grade, Mélodie was transferred to a traditional school. She was evaluated by another special educator and was classified as having a severe learning disability. In fact, she had attained the equivalent of a third grade achievement. She was thus at least 2 school years behind children of her own age who had been in a traditional school since kindergarten.

At this point, we proceeded to administer tests to the child in order to better understand her cognitive structure in a neuropsychological context.

\section{MEASURES}

\section{Intellectual abilities}

A French-Canadian version of the revised Wechsler Intelligence Scale for Children (WISC-R) and a French-Canadian version of the Kaufman Assessment Battery for Children (K-ABC; Kaufman and Kaufman, 1983) were administered. The Faces and Places subtest of the K-ABC was found culturally inappropriate for a French-Canadian child. Its score was thus assigned as the mean score of the total of the Achievement subtests. A French-Canadian vocabulary test (Dayhaw, 1974) was administered in replacement of the analogous WISC-R subtest as well as a French translation of the Verbal Absurdities subtest of the Detroit Tests of Learning Aptitude (DTLA; Baker and Leland, 1967).

\section{Academic abilities}

The investigators obtained the special educator's evaluation of the child's mathematical and writing skills. A reading comprehension test (silent reading comprehension test) was also administered. On this task, the child had to read brief paragraphs as fast as possible and then answer three multiple-choice questions. Another French-Canadian reading test, Gill's diagnostic test of reading (1964), included a timed subtest, requiring the child to compare sentences two by two and to decide whether they were written in a similar way or not, and a second subtest, a vocabulary task, requiring the child to decide whether two words have the same meaning or not. The arithmetic sub- tests of the WISC-R and of the K-ABC were also considered in this section.

\section{Neuropsychological functions}

Four dichotic listening tasks were administered. In the first one, two familiar words were presented dichotically and the child had to say whether a third word was part of the initial pair or not. In the second task, two CV syllables were presented dichotically and the child had to pronounce the syllables heard. The third task resembled the first one but the stimuli were nonsense words. Finally, the fourth task consisted of Kimura's musical task (Kimura, 1964). A tachistoscopic task was designed according to Stroop's paradigm (Stroop, 1935). The stimuli were vertical arranged names of colors (blue, pink and green) each individually appearing randomly in one or the other visual hemifield for $150 \mathrm{~ms}$. The pixel color of the words was discordant with the meaning of each word. The child had to rapidly press a key corresponding to the pixel color, and inhibit lexical-semantic categorization. A 15 -word verbal memory test with interference (Rey, 1966), the adult version of the Trail Making Test Forms A and B (Trites, 1977), the Token Test for children (DiSimoni, 1978) and a Visual Word Desegregation task (Rey, 1970) were also administered. This last test, presented in Fig. 1, consisted of 25 overlapping words written pell-mell. The child had to sort out and read aloud as many words as possible in a limited time period. Finally, a clinical EEG was obtained in order to verify the presence of any atypical hemispheric electrical activity, such as asymmetry, slowness, or abnormal frequency spectra.

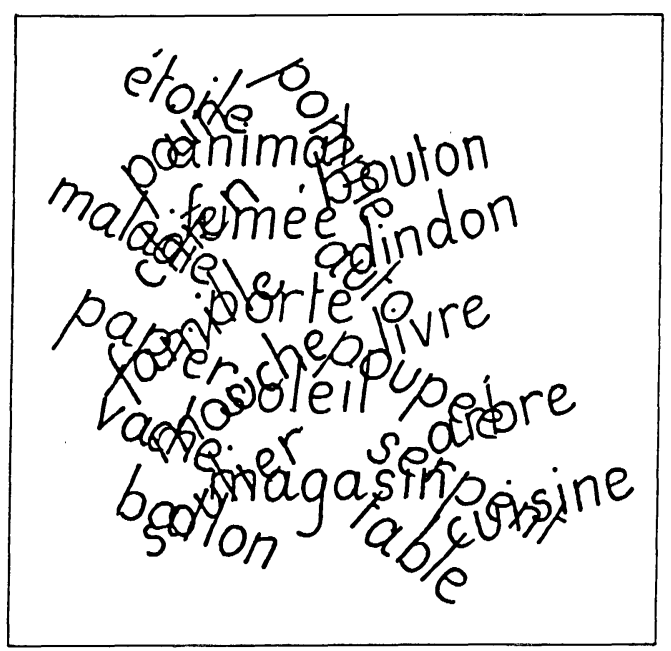

FIG. 1. The Visual Word Desegration task (Rey, 1970). The examinee is required to identify individually, and read aloud, the following French words: animal, arbre, auto, ballon, bouton, chien, cuisine, dindon, étoile, famille, fumée, livre, magasin, maladie, mouche, pain, papier, pomme, porte, poupée, serpent, soleil, soulier, sable, vache. 


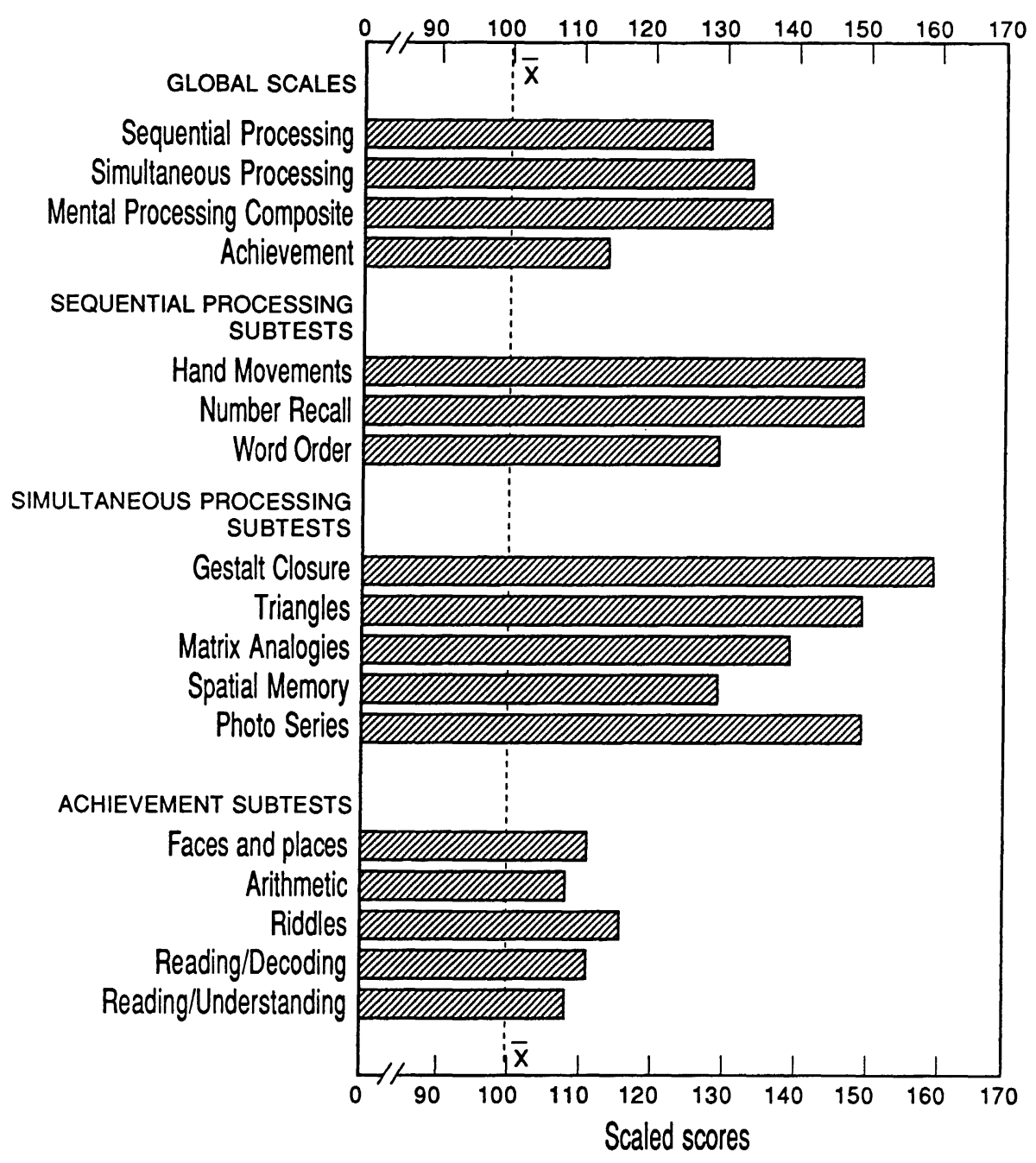

FIG. 2. Mélodie's K-ABC profile. The "simultaneous processing" and "sequential processing" subscale scores are multiplied by 10 so that all measures are on a metric scale comprising a mean of approximately 100 and a standard deviation of approximately 15.

\section{RESULTS}

Intellectual abilities

Mélodie's detailed results on the WISC-R are presented in Fig. 4. Mélodie obtained an "average" score on the verbal scale (VIQ $=96$ ) and a "very superior" score on the performance scale (PIQ = 150). Her full scale was "superior" $(\mathrm{FSIQ}=124)$.

The detailed $\mathrm{K}-\mathrm{ABC}$ results are presented in Fig. 2. The scaled scores of the "sequential processing" and "simultaneous processing" subtests were multiplied by 10 in order to present them with the other scaled scores. According to Kaufman and Kaufman's labeling (1983), Mélodie's sequential processing score was at the boundary of "well above average" and "upper extreme". Her "simultaneous processing", "mental composite processing" and "nonverbal" scores were in the "upper extreme" and her "achievement" score was "above average". No significant difference was found between her ability in "sequential processing" and in "simultaneous processing". However, her "mental processing composite" score was significantly higher than her "achievement" score $(p<0.05)$, suggesting that Mélodie had better developed problem solving aptitudes than ability to use factual knowledge.

Mélodie obtained a raw score of 19 on the vocabulary test. It classified her at a mental age of 14 years. Her raw score on the Verbal Absurdities subtest was 37 placing her at a mental age of 15 years 3 months to 15 years 6 months.

\section{Academic abilities}

Mélodie's results on the special educator's test of mathematical abilities are summarized in Table I. She obtained a mean performance score of $39 \%$. She was thus well under the means of local fifth grade classes $(69-74 \%)$ in traditional schools. 
TABLE I. Mélodie's results on the special educator's test of mathematical abilities

\begin{tabular}{|c|c|c|c|c|c|}
\hline Subjects & Natural numbers & Relational numbers & Geometry & Measurement & $\begin{array}{l}\text { Row } \\
(\%)\end{array}$ \\
\hline Structure & $\begin{array}{l}\text { Order relation }(0 / 4) \\
\text { Numbering and position } \\
\text { of values }(1 / 6)\end{array}$ & $\begin{array}{c}\text { Ordinary } \\
\text { fractioning (8/8) }\end{array}$ & $\begin{array}{l}\text { Polygons (4/6) } \\
\text { Solids (3/4) }\end{array}$ & & 57 \\
\hline \multirow[t]{2}{*}{ Mathematisation } & $\begin{array}{l}\text { Representing of a } \\
\text { situation }(2 / 8)\end{array}$ & & & & 10 \\
\hline & $\begin{array}{l}\text { Meaning of the basic } \\
\text { operations }(0 / 12)\end{array}$ & & & & \\
\hline Operations & $\begin{array}{c}\text { Four basic } \\
\text { operations (6/12) }\end{array}$ & $\begin{array}{l}\text { Representation } \\
\text { of a fraction } \\
(2 / 2)\end{array}$ & $\begin{array}{c}\text { Geometrical } \\
\text { transformations } \\
(0 / 4)\end{array}$ & $\begin{array}{l}\text { Perimeter and } \\
\text { surface }(1 / 4)\end{array}$ & 41 \\
\hline $\begin{array}{l}\text { Analysis and } \\
\text { synthesis }\end{array}$ & Problem solving (1/12) & & & $\begin{array}{l}\text { Problem solving } \\
\qquad(11 / 18)\end{array}$ & 40 \\
\hline $\begin{array}{l}\text { Column } \\
\text { fractions }\end{array}$ & $10 / 54$ & $10 / 10$ & $7 / 14$ & $12 / 22$ & 39 \\
\hline
\end{tabular}

TABLE II. Mélodie's results on the special educator's writing skills test

\begin{tabular}{|c|c|c|}
\hline Abilities & Sub-abilities & Appreciation scale \\
\hline Selectiveness & $\begin{array}{l}\text { Selection of information } \\
\text { Selection of vocabulary }\end{array}$ & $\begin{array}{lllll}5 & 4 & 3 & 2 & 1 \\
5 & 4 & 3 & 2 & 1\end{array}$ \\
\hline Text organisation & Coherence of the text & $5 \underline{4} \overline{3} 21$ \\
\hline Sentence organisation & $\begin{array}{l}\text { Punctuation } \\
\text { Structure }\end{array}$ & $\begin{array}{lllll}5 & \overline{4} & 3 & 2 & 1 \\
5 & 4 & 3 & 2 & 1\end{array}$ \\
\hline Spelling & Spelling & $543 \overline{2} 1$ \\
\hline Grammar & Names, verbs, adjectives & $5432 \overline{1}$ \\
\hline Use of Techniques & Calligraphy & $54 \underline{3} 21$ \\
\hline
\end{tabular}

Mélodie's scaled score on the WISC-R arithmetic subtest was 9 placing her in the average for children of her own age. Her scaled score of 10.9 on the $\mathrm{K}-\mathrm{ABC}$ arithmetic subtest was also in the average range.

Mélodie's results on the special educator's writing skills test are summarized in Table II. The scale runs from 1 to 5 , a score of 1 meaning "well under the success threshold", a score of 2 signifying "under success threshold", a score of 3 being average, a score of 4 indicating "above success threshold" and, finally, a score of 5 corresponding to "well above success threshold". Mélodie's scores varied from 1 to 4 , her more frequent score being 3 .

Mélodie's raw scores on the two subtests of Gill's reading test were 29 for the first subtest and 51 for the second subtest. Her percentile scores were 60 and 98 respectively against norms of 11-year-old normal children. Finally, her raw score on the Lidec reading test was 38 placing her at the 70 th percentile for children her age.

\section{Neuropsychological functions}

Mélodie's results on the tasks of dichotic listening are compared with those of adult literate and illiterate subjects in Table III. Comparison data were collected by Fraile (1987). The child's hemispheric organization clearly resembles that of the literate subjects in that, like them, her left ear showed a superiority on Kimura's musical task while her right ear was superior in the familiar words and nonsense words tasks. No dominance effect was obtained by Mélodie on the CV syllables task. No evidence of atypical organization for Mélodie's verbal functions or musical ability was found in this assessment. Furthermore, she performed as well as illiterate adults on these tasks.

Mélodie's results on the tachistoscopic task were compared to those of young women an average age of 23.5 years and an average education of 14.6 years tested in a previous experimental study in the same research laboratory. The median of Mélodie's reaction times in the left visual field was of $694 \mathrm{~ms}$ while that of the young women was $671 \mathrm{~ms}$. For the right visual field, Mélodie's median was $684 \mathrm{~ms}$ and the women's was $671 \mathrm{~ms}$. Although the child was somewhat slower that the mean of her older sexmates, she showed no atypical asymmetry on the tachistoscopic task.

Mélodie's raw score on the verbal memory task with 
TABLE III. Percentage of success obtained by literate and illiterate subjects and by Mélodie on dichotic listening tasks

\begin{tabular}{lllllll}
\hline Tasks & \multicolumn{5}{c}{ Subjects } \\
\cline { 2 - 7 } & \multicolumn{2}{c}{ Literate } & \multicolumn{2}{c}{ llliterate } & \multicolumn{2}{c}{ Mélodie } \\
\cline { 2 - 7 } & Left ear & Right ear & Left ear & Right ear & Left ear & Right ear \\
\hline Verbal tasks & & & & & & \\
$\quad$ Familiar words & 84.37 & 87.90 & 65.44 & 55.49 & 90.24 & 100.00 \\
$\quad$ CV syllables & 54.89 & 67.61 & 57.39 & 45.83 & 66.67 & 66.67 \\
$\quad$ Nonsense words & 72.81 & 80.10 & 75.19 & 65.20 & 83.33 & 97.50 \\
Musical task & 68.75 & 66.33 & 61.50 & 58.67 & 91.67 & 58.33 \\
$\quad$ Melodies & & & &
\end{tabular}

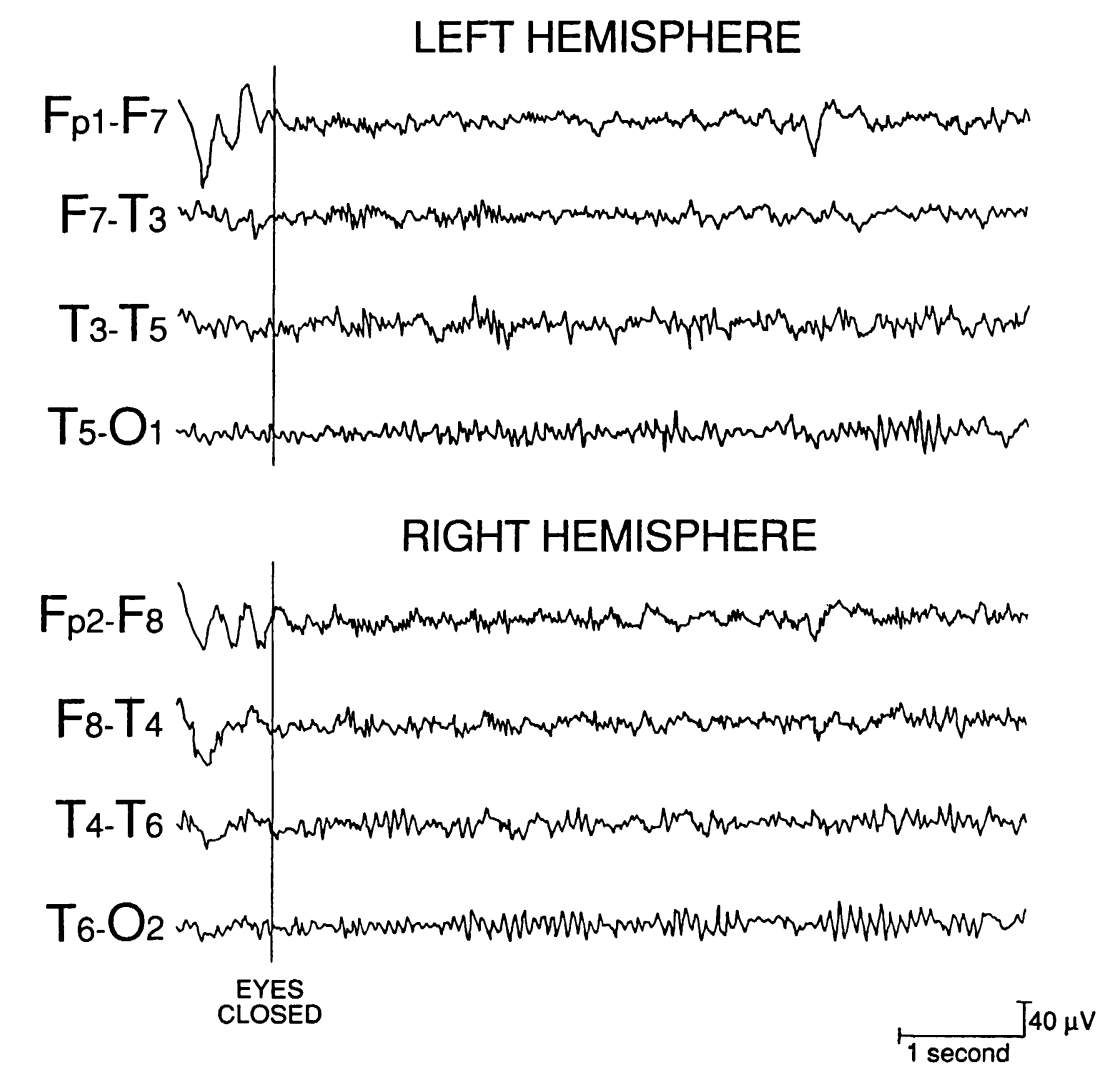

FIG. 3. Sample of tracings from clinical electronencephalographic examination. This particular sample displays at the top, 3 lateral left hemispheric bipolar deviations, and at the bottom, the same deviations over the right hemisphere. At the beginning of the tracings, Mélodie had just been instructed to close her eyes. Note the presence of marked symmetry, normal spectra and absence of further clinical signs.

interference was 57 , placing her at the 50th percentile of children her age. As for the Trail Making Test, Forms A and B, Mélodie was compared to adult subjects with low levels of educational attainment (Bornstein, 1985). She accomplished Form $\mathrm{A}$ in $37 \mathrm{~s}$ and was in the average range of poorly educated adults $(M=33.2$; S.D. $=11.6)$. She accomplished Form $B$ in $68 \mathrm{~s}$ and was again in the average range when compared to poorly educated adults $(\mathrm{M}=86.8$; S.D. $=38.3)$. Mélodie's raw score on the Token Test was 59, placing her in the average range of children her age $(M=54.73)$. Finally, Mélodie identified and read aloud 24 words in 2 min on the Visual Word Desegregation task. This placed her at the 90 th percentile for 11-year-old children. 


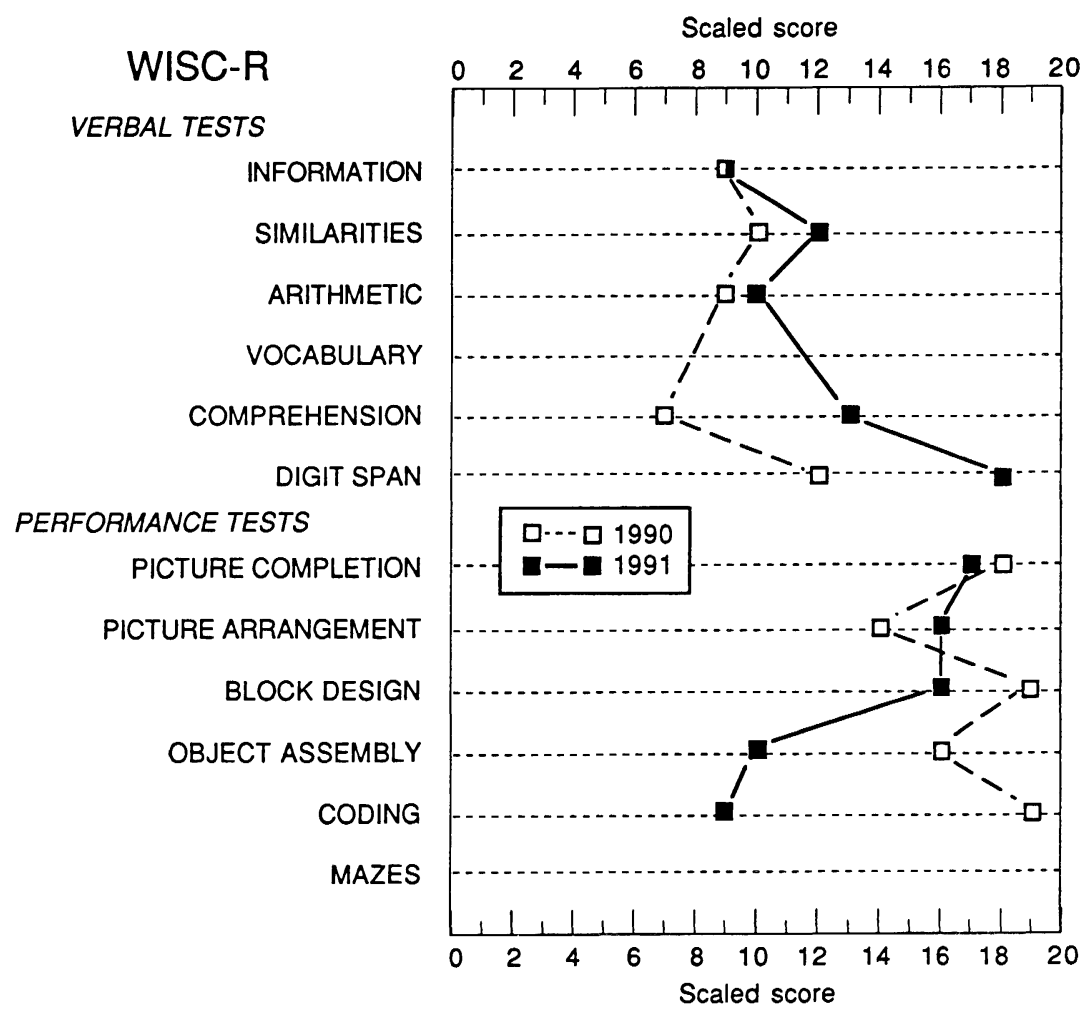

FIG. 4. Mélodie's WISC-R profiles on the first evaluation and on the follow-up evaluation.

Her electroencephalogram is shown in Fig. 3. No abnormal electrical activity was noted.

\section{FOLLOW-UP}

\section{Intellectual abilities}

At the end of her first year in the traditional school, Mélodie was again administered the WISC-R. The results of this follow-up evaluation are presented in Fig. 4. The child obtained a "high average" score on the verbal scale $(\mathrm{VIQ}=114)$ and a "superior" score on the performance scale (PIQ = 126). Her full scale score was "superior" $(\mathrm{FSIQ}=122)$.

\section{Academic abilities}

The academic results of Mélodie's first year at the traditional school were obtained. Concerning her writing skills, the child progressed from "has difficulty in accomplishing the work required" to "can easily accomplish the work required". Concerning her reading skills, she progressed from "can accomplish the work required" to "can easily accomplish the work required". Finally, Mélodie's general arithmetic ability progressed from "has difficulty in accomplishing the work required" to "can easily accomplish the work required".

\section{DISCUSSION}

Clearly, the idea that the child suffered from a cerebral lesion is not supported by the results reported in the present study. Mélodie obtained normal results on dichotic listening, verbal and musical tasks, tachistoscopic tasks, a verbal memory test with interference, the Trial Making Test (Forms A and B), the Token Test and a visual word desegregation task. These tests are fairly sensitive to brain damage (particularly of the left hemisphere) and would probably have detected a left hemispheric lesion or dysfunction (Kimura, 1964, 1967; DiSimoni, 1978; Hugdahl and Franzon, 1985; Killian, 1985). Furthermore, the child's EEG showed no atypical cerebral activity.

The possibility that Mélodie suffered from "severe sequential processing difficulties" was again not verified by her results on the K-ABC. In fact, she performed at the boundary of "well above average" and "upper extreme" on the "sequential processing" scale. No significant discrepancy was found between her score on this scale and her score on the "simultaneous processing" scale.

Mélodie obtained consistently average to superior scores in reading comprehension tests, arithmetic tests, vocabulary tests and a verbal absurdities task, with the exception of the special educator's academic achievement tests. The child did not show any marked difficulty in 
abstract conceptualization, flexibility of thinking, auditory discrimination, short-term memory, word recognition, vocabulary, auditory-verbal functioning, visuo-spatial functioning, attentional capacity, sequential or simultaneous processing, or verbal tasks without visual support. The labeling of severe learning disability remains justified solely on the basis of the child's results on the special educator's tests.

The literature on learning disabilities reveals that learning disabled children with a WISC-R discrepancy in favor of the performance scale show consistent deficiency on the so-called left hemispheric tasks (Rourke et al., 1971, 1983; Petrauskas and Rourke, 1979; Rourke, 1983; Rourke and Fisk, 1988). The left hemisphere tasks are generally language-related and include abilities like auditoryverbal processing, short-term recall of verbal material, verbal processing without visual support, word recognition and speech-sound perception. Mélodie proved that she possessed these abilities in the high average to superior ranges.

The academic achievement tests used by the special educator corresponded, of course, to specific types of abilities normally achieved by children with traditional academic backgrounds. This was most certainly not the case for Mélodie. In fact, as mentioned, she went to alternative schools where her learning of academic subjects was certainly delayed. Nobody ever told her how important it was to read quickly, to do mathematical computations or to write according to grammatical rules. On the contrary, she was taught to write phonetically. She was left free to develop her artistic creativity and her interpersonal skills.

Consequently, it would seem more appropriate to think in terms of "academic underachievement" than of "learning disability" in this case. A "diagnosis" of learning disability suggests that the child is inherently incapacitated. In fact, learning disability is recognized, at least by neuropsychologists, as an intrinsic disorder of basic psychological processes such as understanding and using language, ability to think, read, spell, write, do calculations, excluding the results of environmental and cultural disadvantages, or of poor educational systems (Baird and Gordon, 1983; Spreen et al., 1984).

Finally, it seems interesting to briefly describe the results of a small-scale survey concerning alternative school class-mates of Mélodie who, like her, were transfered to traditional schools before the end of their primary school. But first, a basic fact about alternative school systems should be pointed out. It is believed in this system that a child studying in an alternative school for the whole 6 years of the primary course will be ready to succeed in traditional secondary school classes. The rhythm of learning may vary from child to child but all children will concentrate on academic subjects, at least in the last few years of the primary course, that is, in the fifth or sixth grade. When a child leaves the alternative system in the middle of the primary course, it is recognized that some delay in learning may be encountered. The parents of eight children were contacted and asked to describe the difficulties, if any, that their child had encountered when transferred to a traditional school. Clearly, each of those eight children suffered from average to severe difficulties in academic adjustment. In fact, one repeated three classes, one repeated two classes, four repeated one class and only two were placed at their normal class level. Furthermore, six of those eight children had to follow private classes and required help from the school's special educator. One of the eight children was classified as having great academic difficulties and was put in a severe learning disabilities special group. Finally, and perhaps most interestingly, one of the children, who had to repeat one school year, is presently following courses in a class for gifted children.

We conclude that the 54-point VIQ-PIQ discrepancy in this case was due, primarily, to academic underexposure in unstructured "permissive" primary schools, and possibly secondarily, to an artistically-inclined home environment, and finally, perhaps to a small extent, to a dent in Mélodie's language development due to a 15-month immersion in a foreign culture. This extraordinary discrepancy, observed in a child with an apparently normally functioning brain, demonstrates that the VIQ-PIQ discrepancy must not be "reified" as a neuropsychological index, since it can manifest dramatic changes over time and be very strongly influenced by purely cultural factors. The strong impact of even brief immersion in an "unusual" school environment, and perhaps especially subsequently in a "normal" school environment, on the WISC-R VIQPIQ balance, is striking. Mélodie had learned in the alternative school to be a spontaneous, self-activated, perhaps impulsive, artistically inclined individual. This may have exerted a very strong favorable influence on her ability to accomplish performance subtests on the WISC-R, and may have inclined her to do so extremely rapidly, thereby collecting bonus points for rapid execution-an eventuality which does not apply to the verbal subtests of the WISC-R since these are not timed. After transfer to a traditional school. Mélodie learned to submit to more demanding, prolonged and inherantly less interesting intellectual constraints in the form primarily of verbal instructions of the teacher, and obtained for the first time a great deal of feedback concerning her errors. This probably favored her performance on the verbal subtests of the WISC-R at retest and actually may have caused the marked decline of her score on the performance subtests. She probably simply applied her newly acquired cognitive style (more careful, less impulsive, more self-critical about making errors) and thereby lost the bonus points for rapid execution. 
This case portrays one among perhaps many contexts where misdiagnosis of a "cerebral lesion" on the basis of the WISC-R alone, and misdiagnosis of "severe learning disability" on the basis of achievement testing along, without reference to the child's schooling, might have occurred, and should be avoided in the future.

\section{Acknowledgements}

We are indepted to Francine Lussier and Valérie Fraile for consultation, to the Natural Sciences and Research Council of Canada for providing a bursary to D.L., and to le Fonds Concerté d'Action et de Recherche (Québec) for providing a grant to C.M.J.B.

\section{REFERENCES}

Aram DM and Whitaker HA (1988) Cognitive sequelae of unilateral lesions acquired in early childhood. In: Lateralization in Children (Eds DL Molfese and SJ Segalowitz). Guilford Press, New York.

Baird HW and Gordon EC (1983) Neurological Evaluation of Infants and Children. Spastics International Medical Publications, London.

Baker H and Leland B (1967) Detroit Tests of Learning Aptitude. Bobbs-Merrill, Indianapolis.

Berk RA (1982) Verbal-performance IQ discrepancy score: a comment on reliability, abnormality and validity. Journal of Clinical Psychology, 38, 638-640.

Black FW (1974) WISC verbal-performance discrepancies as indicators of neurological dysfunction in pediatric patients. Journal of Clinical Psychology, 30, 165-167.

Bloom AS Topinka CW, Goulet M, Reese A and Podruch PE (1986) Implications of large WISC/WISC-R verbal-performance IQ discrepancies. Journal of Clinical Psychology, 42, 353-357.

Bornstein RA (1984) Unilateral lesions and Wechsler Adult Intelligence Scale-Revised: no sex differences. Journal of Consulting and Clinical Psychology, 52, 609-615.

Bornstein RA (1985) Normative data on selected neuropsychological measures from a non-clinical sample. Journal of Clinical Psychology, 41, 651-659.

Bornstein RA and Matarazzo J (1982) Wechsler VIQ versus PIQ differences in cerebral dysfunction: a literature review with emphasis on sex differences. Journal of Clinical Neuropsychology, 4, 319-334.

Bryden MP (1988) Does laterality make any difference? Thoughts on the relation between cerebral asymmetry and reading. In: Brain Lateralization in Children (Eds DL Molfese and SJ Segalowitz). Guilford Press, New York.

Dayhaw LT (1941) Une Échelle de Vocabulaire (A vocabulary scale). Institut pédagogique Saint-Georges, Montréal.

Dennis M and Whitaker HA (1976). Language acquisition following hemidecortication: linguistic superiority of the left over the right hemisphere. Brain and Language, 3, 404-433.

DiSimoni F (1978) The Token Test for Children. Teaching Resources, Hingham.

Fraile V (1987) Scolarisation et spécialisation hémisphérique pour les fonctions verbales et musicales (Education and hemispheric specialization for verbal and musical functions). Unpublished master's thesis, Université de Montréal, Montréal.
Gill CE (1964) Test Diagnostique de Lecture (Diagnostic reading test). Institut de Recherches Psychologiques, Montréal.

Grossman FM (1983) Interpreting WISC-R verbal-performance discrepancies: a note for practitioners. Perceptual and Motor Skills, 56, 96-98.

Gutkin TB (1979) WISC-R scatter indices: useful information for differential diagnosis? Journal of School Psychology, 17, 368-371.

Holroyd J (1968) When WISC verbal IQ is low.Journal of Clinical Psychology, 24, 457.

Hooper SR and Hynd GW (1985) Differential diagnosis of subtypes of developmental dyslexia with the Kaufman Assessment Battery for Children (K-ABC). Journal of Clinical Child Psychology, 14, 145-152.

Hudahl K and Franzon H (1985) The incongruent color-words paradigm and language lateralization: an EEG-study. Scandinavian Journal of Psychology, 26, 327-335.

Inglis $\mathbf{J}$ and Lawson $\mathbf{J}(1982)$ Sex differences in the effects of unilateral brain damage on intelligence. Science, 212, 693-695.

Kaufman AS (1976) Verbal-performance IQ discrepancies on the WISC-R. Journal of Consulting and Clinical Psychology, 44, 739-744.

Kaufman AS (1980) Issues in psychological assessment: interpreting the WISC-R intelligently. In: Advances in Clinical Child Psychology (Eds BB Lahey and AE Kazdin). Plenum Press, New York.

Kaufman AS (1981) The WISC-R and learning disabilities assessment: state of the art. Journal of Learning Disabilities, $14,520-526$.

Kaufman AS and Kaufman N (1983) Kaufman Assessment Battery for Children $(K-A B C)$. American Guidance Service, Circle Pines, Minnesota.

Killian GA (1985) The Stroop Color and Word Test. In: Test Critiques (Eds DJ Keyser and RC Sweetland). Test Corporation of America, Kansas City.

Kimura D (1964) Left-right differences in the perception of melodies. Quarterly Journal of Experimental Psychology, 16, 355-358.

Kimura D (1967) Functional asymmetry of the brain in dichotic listening. Cortex, 3, 163-178.

Kolb B and Whishaw IQ (1985) Fundamentals of Human Neuropsychology. W.H. Freeman, New York.

Lecture silencieuse: épreuve de compréhension (Silent reading: a comprehension task). (Date unknown). Lidec Inc., Montréal.

Lueger RJ, Albott WL, Hildendorf WA and Gill KJ (1985) Neuropsychological and academic achievement correlates of abnormal WISC-R verbal-performance discrepancies. Journal of Clinical Psychology, 41, 801-805.

McGlone J (1986) The neuropsychology of sex differences in human brain organisation. In: Advances in Clinical Neuropsychology (Eds G Goldstein and RE Tarter). Plenum Press, New York.

Moffitt TE and Silva PA (1987) WISC-R verbal-performance IQ discrepancy in an unselected cohort: clinical significance and longitudinal stability. Journal of Consulting and Clinical Psychology, 55, 768-774.

Morris GL Levy J and Pirozzolo FJ (1988) Electrophysiological assessment in learning disabilities. In: Assessment Issues in Child Neuropsychology (Eds MG Tramontana and SR Hooper). Plenum Press, New York.

Petrauskas RJ and Rourke BP (1979) Identification of subtypes of retarded readers: a neuropsychological multivariate approach. Journal of Clinical Neuropsychology, 1, 17-37. 
Rey A (1966) Les Troubles de la mémoire et leur Examen Psychométrique (Memory defects and their psychometric evaluation). Dessart, Bruxelles.

Rey A (1970) Examen Clinique en Psychologie (Psychological clinical evaluation). Presses Universitaires de France, Paris. Riva D and Cazzaniga L (1986) Late effects of unilateral brain lesions before and after the first year of age. Neuropsychologia, 24, 423-428.

Rourke BP (1983) Reading and spelling disabilities: a developmental neuropsycholocal perspective. In: Neuropsychology of Language, Reading and Spelling (Ed. U Kirk). Academic Press, New York.

Rourke BP and Fisk JL (1988) Subtypes of learning-disabled children: implications for a neurodevelopmental model of differential hemispheric processing. In: Brain Lateralization in Children (Eds DL Molfese and SJ Segalowitz). Guilford Press, New York.

Rourke BP, Bakker DJ, Fisk JL and Strang JD (1983) Child Neuropsychology: An Introduction to Theory, Research, and Clinical Practice. Guilford Press, New York

Rourke BP, Young GC and Flewelling RW (1971) The relationships between WISC verbal-performance discrepancies and selected verbal, auditory-perceptual, visual-perceptual and problem-solving abilities in children with learning disabilities. Journal of Clinical Psychology, 27, 475-479.

Ryckman DB (1981) Searching for a WISC-R profile for learning disabled children: an inappropriate task? Journal of Learn- ing Disabilities, 14(7)

Saklofske DH Schmidt HPJ and Yackulic RA (1984) Variations in WISC-R patterns of learning disabled children. Perceptual and Motor Skills, 59, 415-421.

Schiff MM Kaufman AS and Kaufman NL (1981) Scatter analysis of WISC-R profiles for learning disabled children with superior intelligence. Journal of Learning Disabilities, 14(7).

Spreen O, Tupper D, Risser A, Tuokko H and Edgell D (1984) Human Developmental Neuropsychology. Oxford University Press, New York.

Stroop JR (1935) Studies of interference in serial verbal reactions. Journal of Experimental Psychology, 6, 643-662.

Tabachnick BG (1979) Test scatter on the WISC-R. Journal of Learning Disabilities, 12, 626-628.

Thompson RJ (1980) The diagnostic utility of WISC-R measures with children referred to a developmental evaluation center. Consulting and Clinical Psychology, 48, 440-447.

Trites RL (1977) Neuropsychological Test Manual. Royal Ottawa Hospital, Ottawa.

Vargha-Khadem F, O'Gorman AM and Watters GV (1985) Aphasia and handedness in relation to hemispheric side, age at injury and severity of cerebral lesion during childhood. Brain, 108, 677-696.

Wechsler D (1955) Wechsler Adult Intelligence Scale. Psychological Corporation, New York.

Wechsler D (1974) Wechsler Intelligence Scale for ChildrenRevised. Psychological Corporation, New York. 


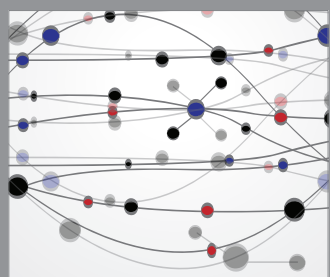

The Scientific World Journal
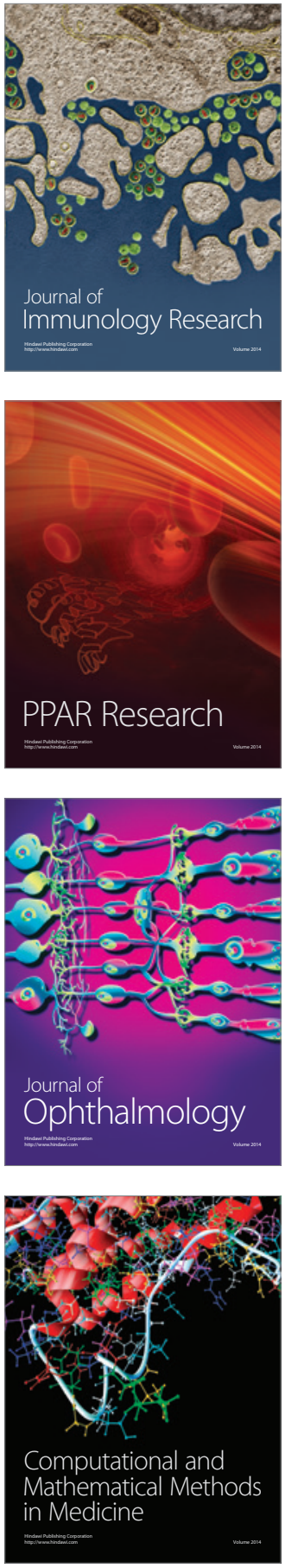

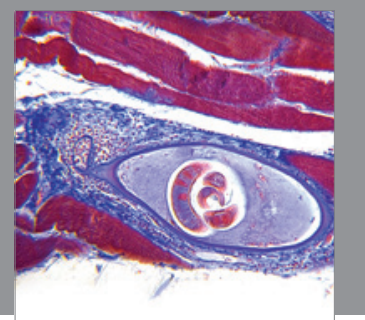

Gastroenterology

Research and Practice


\section{Hindawi}

Submit your manuscripts at

http://www.hindawi.com
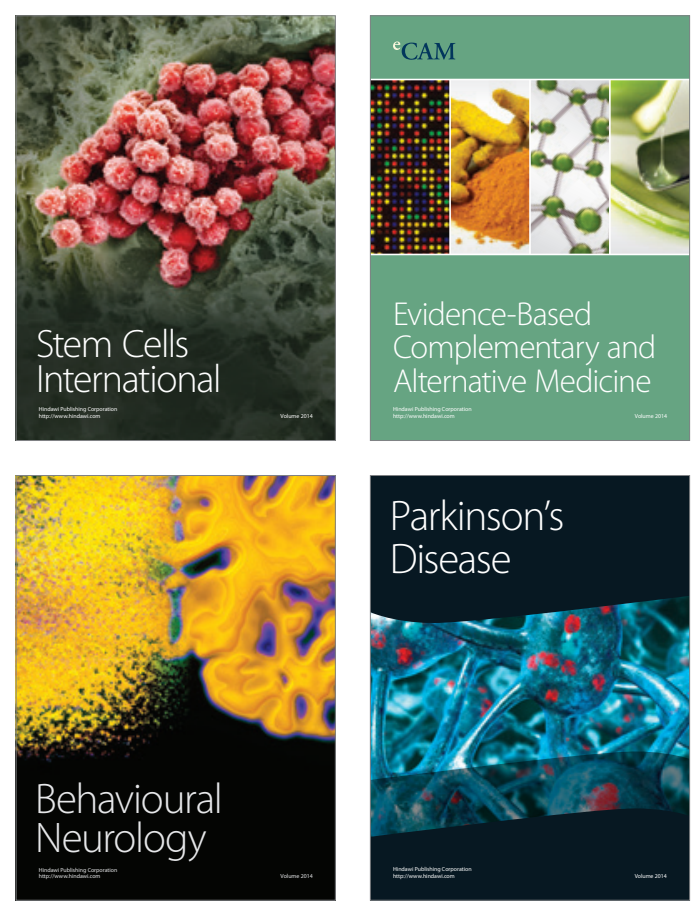

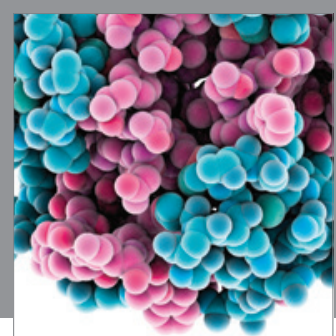

Journal of
Diabetes Research

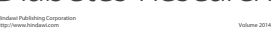

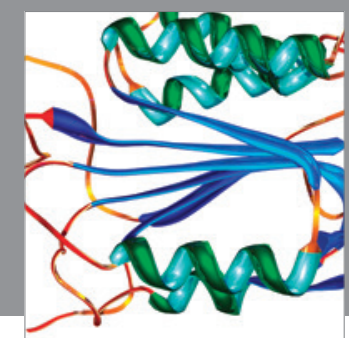

Disease Markers
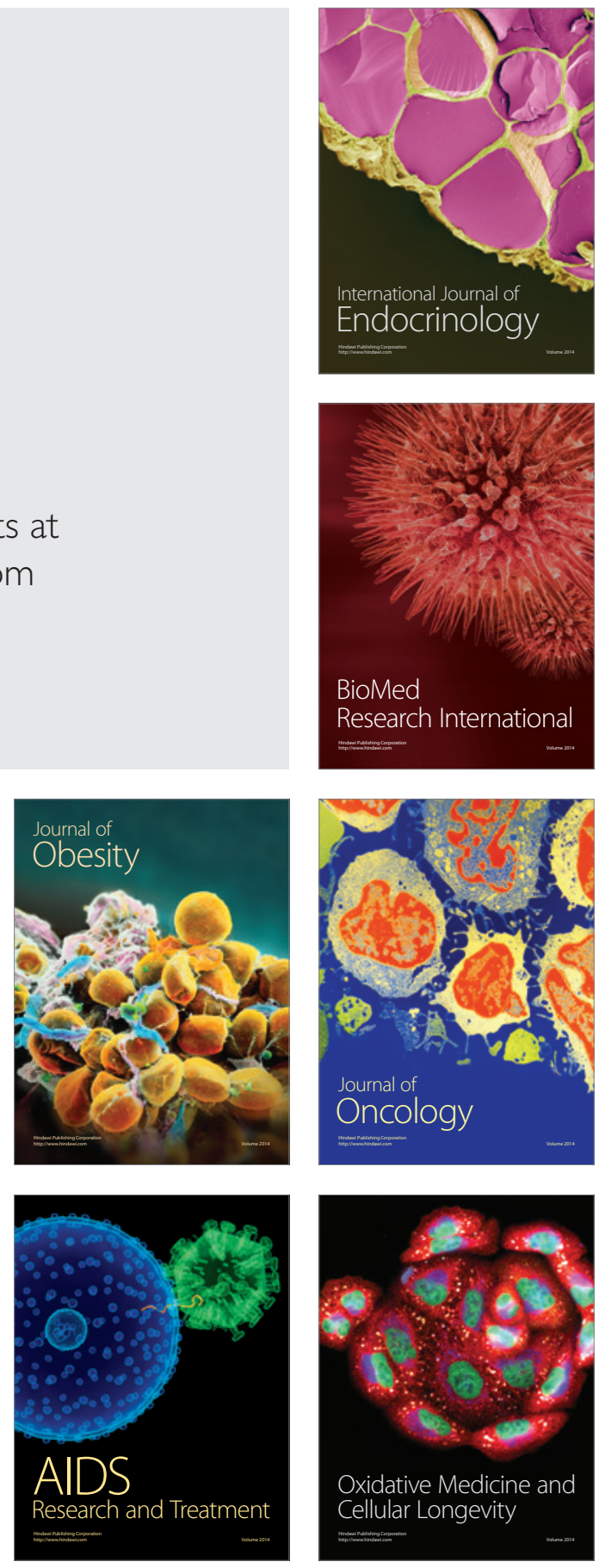